\title{
Study on Fast Charging Method of Lead-Acid Battery for Electric Vehicle
}

\author{
Yuanpeng $\mathrm{Zhu}^{1, \text { a }}$ \\ ${ }^{1}$ School of Automotive Engineering, Wuhan University of Technology, Wuhan 430070, China \\ awhutyuanpeng@whut.edu.cn
}

Keywords: electric vehicle; lead-acid battery; fast charging method

\begin{abstract}
The lead acid batteries used by electric vehicles have always presented the problem of low efficiency and high loss. In order to promote the popularization and application of electric vehicles, many researchers have put forward the fast charging method of battery. Based on this understanding, the fast charging principle of battery was analyzed in this paper, and the depolarization pulse fast charging method and the high current decline fast charging method were studied, so as to provide reference for the people interested in the topic.
\end{abstract}

\section{Introduction}

The lead-acid battery as a kind of battery with mature technology and low cost has been applied in electric vehicle. However, electric vehicle has always presented the problem of short mileage with charging once, which has hindered the development of electric vehicle. In addition, the battery will suffer from rapid temperature rise which ultimately affects the battery life instead of reaching the rated capacity only through increasing the charging current and shortening the charging time. Therefore, it is necessary to strengthen the study on fast charging method of lead-acid battery for electric vehicle, in order to better promote the development of electric vehicles.

\section{Analysis of the fast charging principle of lead-acid battery for electric vehicle}

In practical applications, the lead-acid batteries for electric vehicles use the constant current charging, constant voltage charging, phased charging and other conventional charging methods. Although it is easier to implement the conventional charging methods and control them simply, more than ten hours of charging time is needed, which not only affects the use of electric vehicles, but also damages the batteries. In addition, according to the technical parameters of lead-acid battery proposed by the Advanced Lead Acid Battery Consortium (ALABC) (as shown in Table 1), these fast charging methods cannot meet the demand of the battery for electric vehicle.

Table 1: technical parameters of lead-acid battery

\begin{tabular}{clll}
\hline $\begin{array}{c}\text { Charging } \\
\text { Requirements }\end{array}$ & $50 \%$ Capacity & $80 \%$ Capacity & $80 \%$ Capacity \\
\hline $\begin{array}{c}\text { Charging } \\
\text { Time }\end{array}$ & $5 \mathrm{~min}$ & $15 \mathrm{~min}$ & $4 \mathrm{~h}$ \\
\hline
\end{tabular}

\subsection{Analysis of main factors hindering the battery charging}

As can be seen from the analysis of the reasons hindering the battery charging, polarization phenomenon will appear between the two poles in the late charge. At this time, the potential difference between the two poles will be higher than the equilibrium electrode potential of the active substance, thereby influencing the battery charging capacity. With the increase of charging current, electrochemical polarization reaction will increase significantly, thereby decreasing the battery charging capacity [1]. Thereby, it is necessary to seek ways to eliminate the battery polarization phenomenon, rather than simply increase the charging current, so as not to affect the service life of the battery. 


\subsection{Fast charging principle of lead-acid battery}

As can be seen from the analysis of battery charging process, the acceptable charging current of the battery decreased with the time. The formula for calculating the charging current is ${ }^{\mathrm{i}_{c}}=I e^{-\alpha t}$, of which ic is the charging current, $\mathrm{I} 0$ is the maximum acceptable charging current of the battery at time 0 , and $\alpha$ is the attenuation coefficient. Therefore, it is necessary to ensure that the charging current is always in the range of the maximum charging current of the battery, so that the battery is in the best state of acceptance. In the case of the charging time is 0 , the battery can accept the maximum charging current. Therefore, in the early stage of charging, larger charging current can be used [2]. Currently, the fast charging methods of lead-acid battery can be divided into two kinds, namely pulse fast charging method and high current decline fast charging method.

\section{Fast charging methods of lead-acid battery for electric vehicle}

\subsection{Depolarization pulse fast charging method}

The so-called depolarization pulse fast charging method, in fact, realizes short stop charging in the process of high current charging and adds discharge pulse in the process of stop charging. In the charging process of lead-acid battery, addition of negative pulse with certain height, width and frequency in the current can increase the concentration of lead ions participating in reaction, and moves other negative ions away from the electrode surface, so as to reduce the probability of polarization phenomena, and therefore increase the acceptable charging current of the battery. As shown in Fig. 1, curve 0 is the acceptable charging current curve at the deep discharge phase of the battery; curve 1,2, 3 and 4 are the acceptable charging current curves of the battery after charged for a period of time and discharge of negative pulse. As can be seen from the figure, other curves shift right compared with curve 0 . This phenomenon means that the battery charging capacity is enhanced.

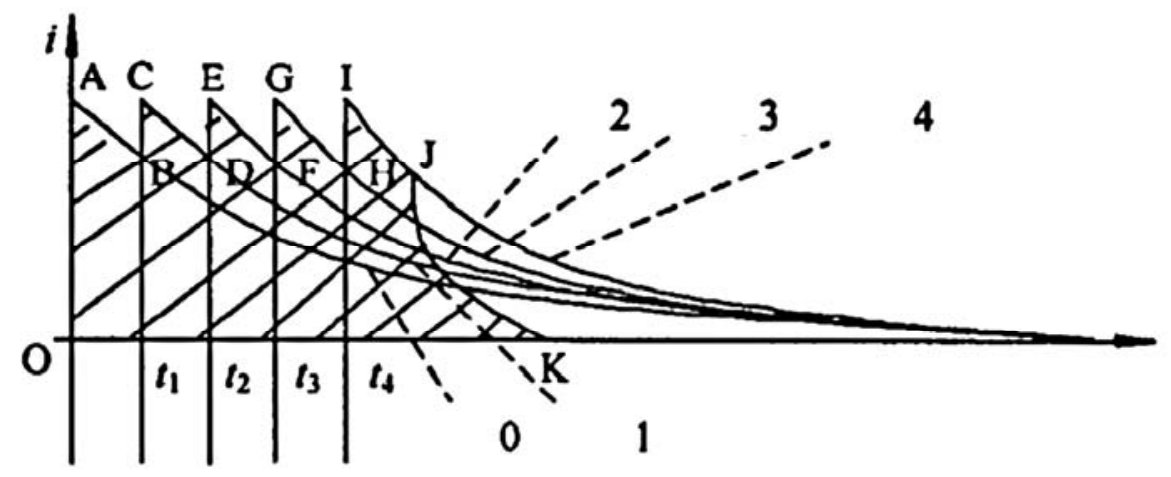

Fig. 1: acceptable current changes of negative pulse depolarization

According to the charging principle of depolarization pulse fast charging method, it is found that the charging current of this kind of charging method is larger. With the increase of the battery capacity, terminal voltage of the battery will also increase. After the completion of the first phase of the charging, you can stop charging $25-40 \mathrm{~ms}$, in order to completely eliminate the ohmic polarization and partial concentration polarization. Subsequently, reverse charge can be conducted, making the battery pass through the larger pulse current [3]. The width of the pulse current is $25-200 \mathrm{~ms}$, and the amplitude is 2-5 times of the charging current, which can further eliminate the concentration polarization. After the stage charging is completed, $25 \mathrm{~ms}$ of stop discharging can be conducted again, and then the cycle charge of positive pulse charging-forward pause-negative pulse discharge-rear pause-positive pulse charging can be conducted until the battery voltage reach a certain value.

In order to study the charging effect of depolarization pulse fast charging method, charging test can be conducted by means of $2 \mathrm{~V} / 200 \mathrm{Ah}$ lead-acid battery. Specifically, $25 \mathrm{~ms}$ of pause was conducted after charged $2 \mathrm{~min}$ by using $170 \mathrm{~A}$ current. Then, $50 \mathrm{~ms}$ of negative pulse discharge was conducted by using 300A current, and $25 \mathrm{~ms}$ of pause was conducted. On this basis, high current charging can be continued, and cycle charging can be conducted. As shown in Table 2 below, output capacity of the battery would reach $61 \%$ after the actual charge of $90 \mathrm{~min}$. However, it takes 8 hours to 
reach the output capacity by using the conventional constant current charging method. Therefore, it can be seen that the application of the depolarization pulse fast charging method has achieved certain results.

Table 2: effect of depolarization pulse fast charging method

\begin{tabular}{llll}
\hline $\begin{array}{c}\text { Charging } \\
\text { Time/h }\end{array}$ & Terminal Voltage/V & Charging Current/A & Capacity/Ah \\
\hline 0 & 11 & 170 & 0 \\
0.3 & 13 & 170 & 47 \\
0.6 & 15 & 170 & 92 \\
0.9 & 16 & 170 & 132 \\
1.5 & 17 & 60 & 159 \\
2.0 & 18 & 10 & 164 \\
3.0 & 18 & 5 & 169 \\
\hline
\end{tabular}

3.2 High current decline fast charging method

For the charging acceptance ratio of the battery $\mathrm{a}=\mathrm{I} 0 / \mathrm{C}, \mathrm{C}$ is the battery capacity. In the case of smaller battery capacity, the charging acceptance ratio of the battery will increase obviously. Therefore, the high current decline fast charging method realizes charging by using the high current in the initial stage of charging based on the feature of the battery in the low state of charge [4]. With the increase of charging time, current difference will gradually reduce, and ultimately be lower than certain current value, until the battery capacity is sufficient.

In order to study the application effect of the high current decline fast charging method, 300Ah battery can be used as an example to charge the battery with 500A current. During the charging process, the current is reduced by using 50A difference at regular time, until the current reduces to 100A. As shown in Fig.2 below, the graph shows a charging curve of the high current decline fast charging method; the output capacity of the battery will reach $63 \%$ when the charging time reaches $46 \mathrm{~min}$.

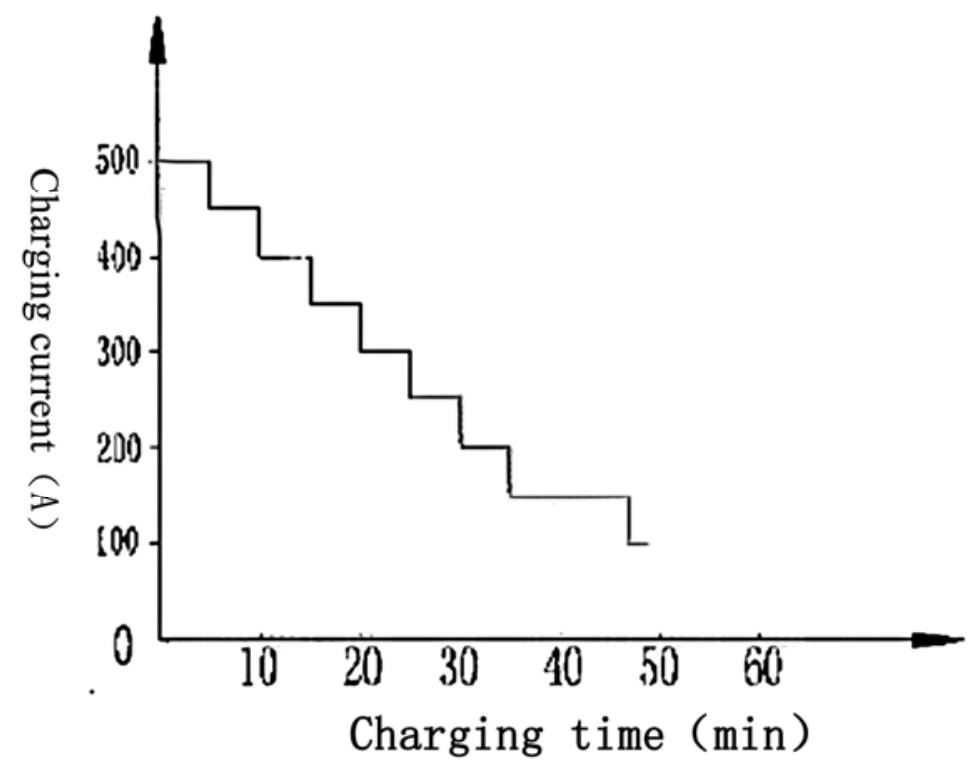

Fig. 2: charging curve of the high current decline fast charging method

Conclusion: all in all, shortening the charging time of lead-acid battery will be conducive to the application of electric vehicles. Currently, however, there is no more mature charging technology in the fast charging of lead-acid batteries in electric vehicles. Although the depolarization pulse fast charging method and high current decline fast charging method can shorten the charging time of lead-acid battery to a certain extent, they are not able to reach the charging requirements of lead-acid batteries proposed by the Advanced Lead Acid Battery Consortium (ALABC). Therefore, it is 
believed that with the development of related technologies, the fast charging method of battery will be further developed, so as to better meet the needs of the development of electric vehicles.

\section{References:}

[1] Chen Hao, Guo Lijin and Li Hui, Intelligent Charging and Its Strategy for Lead-Acid Batteries of Electric Vehicles [J]. Electronic Science and Technology, 2012, 11:79-81.

[2] Ma Yongquan, Liu Xiaowei, Chen Tixian et al. Research on Lead-Acid Batteries for New Energy Vehicles [J]. Battery, 2011, 03:99-103.

[3] Wang Jian, Lv Rongguan and Jiao Changmei, Study on Battery Charging and Its Management for Electric Vehicles [J]. Battery, 2011, 05:230-236.

[4] Duan Zhaowei, Zhang Lei and Liu Gang, Design of Pulse Fast Charging System for Lead-Acid Batteries of Electric Vehicles [J]. Process Automation Instrumentation, 2013, 07:75-77. 